\title{
Tumores metastásicos en pene (II)
}

\author{
C. Pellicé i Vilalta \\ Doctor en Medicina y Cirugía. Urólogo. Barcelona. \\ Actas Urol Esp 2006; 30 (1): 95
}

\section{Sr. Director:}

Recientemente se ha publicado en la revista Actas Urológicas Españolas una "Nota Clínica", titulada:

Retención urinaria aguda y hematuria secundarias a metástasis peneanas por carcinoma renal de células claras (Actas Urol Esp 2005;26: 593-595)

Los autores refieren de un modo correcto lo fundamental a conocer acerca de tan atípica entidad y hay que destacar la aportación de una clara y convincente iconografía.

No obstante al revisar la bibliografía de la mencionada "Nota Clínica" es patente la falta total y absoluta de citas en revistas urológicas españolas, en lengua castellana y redactadas por autores españoles.

Realmente, Sr. Director, no son muchas las referencias bibliográficas de tumores metastáticos peneanos por tumor primario renal en nuestra literatura, pero algunas hay y en su mayoría, han sido publicadas en esta revista de su Dirección. Así yo ya lo manifesté, tiempo atrás y en una anterior "Carta al Director" publicada en Actas Urológicas Españolas ${ }^{1}$. Esta hacía referencia a la cita 2 de la bibliografía adjunta. Indicando que las citas 3 y 4 lo eran por tumores de la pelvis renal.

Presumiblemente quepa atribuir a Ramos et al. en $1982^{5}$, la primera aportación española sobre el tema. Hasta la publicación de la cita de Pascual et al. del $2005^{6}$, han habido otras:
Hernaez, et al. en $1985^{3}$, Llopis, et al. en $1986^{4}$, Marchal, et al. en 19937 , Morga, et al. en 2000 y $2002^{8,9}$ y Herrera, et al. en $2002^{2}$ y ya recientemente y coetánea a ésta ${ }^{2}$ la de Pérez, et al. en $2005^{10}$.

\section{REFERENCIAS}

1. Pellicé C. (Jr): Cartas al Director/Tumores metastásicos en pene. Actas Urol Esp 2003;27:248.

2. Herrera J, Herrera J, López C, Cermeño F, Pierna J, Isusquiza I, et al. Metástasis peneana de un carcinoma de células renales. Actas Urol Esp 2002;26:589-591.

3. Hernaez I, Auteneche JJ. Metástasis peneana de un carcinoma transicional renal.Actas Urol Esp 1985;9:435-436.

4. Llopis B, Alonso F, Valls B, Moreno F, Boronat J, Iranzo S, et al. Tumores secundarios de pene. Actas Urol Esp 1986;10:167-170.

5. Ramos J, González J, Gómez VR, Montero J. Priapismo como primera manifestación de un hipernefroma. Actas Urol Esp 1982;6:373-376.

6. Pascual C, Nieto MA, Luján M, Santonja C, Rodríguez N, Berenguer A. Retención urinaria aguda y hematuria secundarias a metástasis peneanas por carcinoma renal de células claras. Actas Urol Esp 2005;29:593-595.

7. Marchal C, Contreras J, Chicharro JA, Díaz F, Fúnez R, Martín A, et al. Enfermedad metastásica del pene. A propósito de tres casos. Actas Urol Esp 1993;17:461-463.

8. Morga JP, Ferrero R, Guzmán PL, Navas J, García J, García, et al. Priapismo metastático. Presentación de cuatro casos y revisión de la literatura. Arch Esp Urol 2000;53:447-452.

9. García F, Tomás J, Rico M, Sempere JL, Morga A, Fontana LO. Infiltración neoplásica del pene secundaria a tumores de origen diverso. Nuestra experiencia. Congreso Nacional de Urología (AEU: Murcia; 2002) (Abstract: P183)

10. Pérez DA, Blanco M, Toucedo V, Lema L, Cimadevila A, Villar, M. Carcinoma renal metastático de localización atípica. Revisión de la literatura. Actas Urol Esp 2005;29: 621-630

Dr. C. Pellicé i Vilalta

e-mail: 15256cpv@comb.es 